\title{
Relaxin inhibits effective collagen deposition by cultured hepatic stellate cells and decreases rat liver fibrosis in vivo
}

E J Williams, R C Benyon, N Trim, R Hadwin, B H Grove, M J P Arthur, E N Unemori, $\mathrm{J}$ P Iredale

\begin{abstract}
Background-Following liver injury, hepatic stellate cells (HSC) transform into myofibroblast-like cells (activation) and are the major source of type I collagen and the potent collagenase inhibitors tissue inhibitors of metalloproteinases 1 and 2 (TIMP-1 and TIMP-2) in the fibrotic liver. The reproductive hormone relaxin has been reported to reduce collagen and TIMP-1 expression by dermal and lung fibroblasts and thus has potential antifibrotic activity in liver fibrosis.
\end{abstract}

Aims-To determine the effects of relaxin on activated HSC.

Methods-Following isolation, HSC were activated by culture on plastic and exposed to relaxin $(1-100 \mathrm{ng} / \mathrm{ml})$. Collagen deposition was determined by Sirius red incorporation. Matrix metalloproteinase (MMP) and TIMP expression were assessed by zymography and northern analysis. Transforming growth factor $\beta 1$ (TGF-ß1) mRNA and protein levels were quantified by northern analysis and ELISA, respectively.

Results-Exposure of activated HSC to relaxin resulted in a concentration dependent decrease in both collagen synthesis and deposition. There was a parallel decrease in TIMP-1 and TIMP-2 secretion into the HSC conditioned media but no change in gelatinase expression was observed. Northern analysis demonstrated that primary HSC, continuously exposed to relaxin, had decreased TIMP-1 mRNA expression but unaltered type I collagen, collagenase (MMP-13), alpha smooth muscle actin, and TGF- $\beta 1$ mRNA expression.

Conclusion-These data demonstrate that relaxin modulates effective collagen deposition by HSC, at least in part, due to changes in the pattern of matrix degradation.

(Gut 2001;49:577-583)

Keywords: relaxin; hepatic stellate cell; hepatic fibrosis; type I collagen

Correspondence to: $\mathrm{J}$ Iredale, Liver Research Group, Division of Cell and Molecular Medicine, Mail Point 811, Southampton General Hospital, Southampton SO16 6YD, UK.jpi@soton.ac.uk

Accepted for publication 26 February 2001

Liver fibrosis is characterised by increased hepatic deposition of extracellular matrix proteins, particularly type I collagen. An overwhelming body of evidence indicates that the hepatic stellate cell (HSC, lipocyte, fat storing, or Ito cell) is the pivotal effector cell in hepatic dye binding and radiolabelled proline

fibrogenesis. ${ }^{12}$ Following liver injury HSC become activated, proliferate, and undergo transformation to a myofibroblast-like phenotype. In addition to expressing matrix proteins, particularly type I collagen, ${ }^{34}$ activated HSC also express matrix degrading metalloproteinases and the potent metalloproteinase inhibitors tissue inhibitor of metalloproteinases 1 and 2 (TIMP-1 and TIMP-2)..$^{5-9}$ We and others have postulated that progression of fibrosis results from increased synthesis of extracellular matrix molecules coupled with elevated expression of TIMP-1 and TIMP-2. Antifibrotic strategies might therefore usefully be targeted towards either reducing matrix synthesis or increasing matrix degradation.

Relaxin, an insulin-like growth factor hormone, is detectable in serum during pregnancy and plays an important role in initiating the structural remodelling of the cervix and interpubic ligament in preparation for parturition. ${ }^{10-12}$ Studies suggest the effects of relaxin are mediated by both a decrease in collagen synthesis and an increase in the production of collagenase and proteoglycanase. ${ }^{13} 14$ These observations have led to an interest in the potential role of relaxin as an antifibrotic agent. Human skin fibroblasts stimulated to overproduce collagens by inflammatory cytokines respond to relaxin by decreasing their production of type I and III collagens and increasing their synthesis and secretion of procollagenase, and by decreasing TIMP-1 expression. ${ }^{15}$ Similarly, scleroderma fibroblast lines decrease their excessive expression of type I collagen in response to treatment with relaxin. ${ }^{16}$ These results suggest that in vitro, relaxin may modulate matrix turnover in favour of degradation in situations of collagen overexpression.

In vivo, recombinant human relaxin reduced collagen accumulation in a rodent model of dermal fibrosis and was associated with an alteration in the organisation of collagen fibrils within the interstitium. ${ }^{17}$ Subsequently, relaxin was demonstrated to significantly reduce collagen accumulation in a bleomycin induced murine model of lung fibrosis. ${ }^{18}$ Evidence from a model of renal fibrosis suggests that the antifibrotic effect of relaxin may in part be

Abbreviations used in this paper: HSC, hepatic stellate cells; TIMP, tissue inhibitor of metalloproteinases; MMP, matrix metalloproteinase; $\alpha$-SMA, alpha smooth muscle actin; TGF- $\beta 1$, transforming growth factor $\beta 1$; DMEM, Dulbecco's minimal essential medium; PBS, phosphate buffered saline; BSA, bovine serum albumin; TCA, trichloracetic acid; $\mathrm{CCl}_{4}$, carbon tetrachloride. 
mediated by downregulation of transforming growth factor $\beta 1$ (TGF- $\beta 1$ ). ${ }^{19}$ Moreover, in some systems, TGF- $\beta 1$ has been reported to, in turn, inhibit relaxin release. ${ }^{20}$

In the studies reported here, we have examined the effect of recombinant human relaxin on expression of type I collagen, TIMPs, and matrix metalloproteinases (MMPs) in culture activated HSC. Our results indicate that relaxin reduces effective collagen deposition which may result directly from downregulation of type I collagen synthesis and indirectly due to a decrease in TIMP-1 synthesis by HSC, effects that are probably not mediated by endogenous TGF- $\beta 1$ expression.

\section{Methods}

HSC ISOLATION AND CULTURE

HSC were isolated from normal male SpragueDawley rats and cultured as previously described. ${ }^{7}$ Cultures were exposed to recombinant human relaxin 1-100 ng/ml (Lot 63601; Connetics Corp., Palo Alto, California, USA) either continuously from isolation or from days 5-7 (activated HSC) for varying periods of time as stated. To provide confluent monolayers of activated cells for collagen synthesis assays, activated rat and human HSC ( $>7$ days in primary culture) were passaged into multiwell plates. $^{21}$

QUANTIFICATION OF COLLAGEN DEPOSITION BY CULTURED HSC

Primary HSC (activated by culture on plastic in the presence of serum) were exposed to relaxin $1-100 \mathrm{ng} / \mathrm{ml}$ for 48 hours. Cells were washed and collagen deposited in the wells was stained with Picro Sirius red dye, as described by the manufacturer (Biocolor, Belfast, UK). ${ }^{22}$ Unbound dye was removed by washing and the bound complex dissolved in $0.5 \%$ sodium hydroxide. Collagen was quantitated by spectrophotometry at $540 \mathrm{~nm}$ and results were expressed as a percentage of the untreated controls.

QUANTIFICATION OF COLLAGEN PRODUCTION BY CULTURED HSC

Collagen synthesis by HSC was determined by measuring incorporation of ${ }^{3} \mathrm{H}$ proline into collagenous proteins using modifications of the methods of Postlewaite and colleagues ${ }^{23}$ and Cairns and Walls. ${ }^{24}$ Early passaged HSC were seeded into 12 well plates and grown until approaching confluence. Cells were made serum free by washing and incubated in fresh Dulbecco's minimal essential medium (DMEM) supplemented with antibiotics, $25 \mu \mathrm{g} / \mathrm{ml}$ ascorbic acid, $0.01 \%$ bovine serum albumin (BSA), and recombinant relaxin $0-100 \mathrm{ng} / \mathrm{ml}$ in a total volume of $500 \mu \mathrm{l} /$ well. After 24 hours the media was replaced with fresh media containing the same additions as above plus $1 \mu \mathrm{Ci} \mathrm{L}-\left[2,3,4,5-{ }^{3} \mathrm{H}\right]$ proline (Amersham, Little Chalfont, UK) per well. After a further 24 hours the cell supernatants were harvested and the cells lysed in TE $(10 \mathrm{mM}$ Tris $\mathrm{HCl}, 1 \mathrm{mM}$ EDTA, pH 7.5) for DNA quantification.

The supernatants were divided into $4 \times 100 \mu \mathrm{l}$ aliquots and loaded onto 96 well multiscreen filtration plates (Millipore UK Ltd, Watford, UK) and assayed in duplicate either to measure total protein production or production of proteins resistant to digestion by a highly purified bacterial collagenase (non-collagenous proteins). Collagen production per well was calculated using the following formula:

$\left[{ }^{3} \mathrm{H}\right.$ proline incorporation (total protein) $]-\left[{ }^{3} \mathrm{H}\right.$ proline incorporation (noncollagenous protein)]/DNA content ( $\mu \mathrm{g} /$ well)

A total of $35 \mu$ of $0.2 \mathrm{M}$ Tris $/ 0.3 \mathrm{M}$ calcium chloride $\mathrm{pH} 7.5$ and $15 \mu \mathrm{l}$ of $50 \mathrm{mM}$ $N$-ethylmalemide were added to each well while in addition $50 \mathrm{U} /$ well of a highly purified bacterial collagenase (Worthington Biochem Corporation, New Jersey, USA) was added to the wells assigned to determine noncollagenous protein production. The plates were incubated at $37^{\circ} \mathrm{C}$ for 90 minutes. Proteins were then precipitated using 50\% trichloroacetic acid (TCA) and incubation on ice for one hour. The plates were washed with $10 \%$ TCA and the incorporated radioactivity per well determined by scintillation scanning.

\section{DNA QUANTIFICATION}

HSC that had been cultured in the presence or absence of varying concentrations of relaxin were lysed in phosphate buffered saline (PBS) or TE, sonicated, and the DNA content determined by addition of bisbenzamidazole (Hoescht 33258) (Millipore) or PicoGreen (Molecular Probes, Leiden, the Netherlands) and then quantified by fluorometry. ${ }^{25}$

COLLECTION OF CONDITIONED MEDIA AND

EXTRACTION OF RNA FROM HSC

HSC cultured for varying times in serum containing media were washed three times in serum free DMEM and incubated in $2.5 \mathrm{ml}$ of fresh serum free media containing antibiotics and $0.01 \%$ BSA with relaxin $1-100 \mathrm{ng} / \mathrm{ml}$ for varying periods of time as described previously. The media were collected and clarified by centrifugation. Cell monolayers were lysed in $4 \mathrm{M}$ guanidinium isothiocyanate after which RNA was isolated by the acid/phenol method as described previously. ${ }^{26}$

\section{ZYMOGRAPHY/REVERSE ZYMOGRAPHY}

Metalloproteinases and TIMPs were detected by gelatin substrate zymography and reverse zymography, respectively, as previously described. $^{15} 18$

QUANTITATION OF COLLAGENASE

Collagenase activity was measured in conditioned media from primary or early passage HSC that had been cultured continuously with relaxin $100 \mathrm{ng} / \mathrm{ml}$ for 1-3 days, as previously described. $^{21}$

\section{NORTHERN ANALYSIS}

Aliquots of $10 \mu \mathrm{g}$ of total RNA were electrophoresed and transferred to nylon membranes. Probes for TIMP-1, MMP-13, type I collagen, alpha smooth muscle actin ( $\alpha$-SMA), TGF- $\beta 1$, and $\beta$-actin were transcribed from the relevant cDNA using the Megaprime DNA labelling kit (Amersham), and $\left[\alpha_{-}{ }^{32} \mathrm{P}\right]$ ATP (Amersham). 
After overnight hybridisation the membranes were washed at $55^{\circ} \mathrm{C}$ in $0.2 \%$ sodium dodecyl sulphate/0.15 M sodium chloride, $0.015 \mathrm{M}$ sodium citrate, $\mathrm{pH} 7$, and exposed to $x$ ray film at $-70^{\circ} \mathrm{C}$ or to a Storm phosphor imager screen (Molecular Dynamics, Sunnyvale, California, USA).

TGF- $\beta 1$ QUANTITATION

Active and total TGF- $\beta 1$ in the conditioned media of cultured HSC were measured using a commercial ELISA (R\&D Systems, Abingdon, UK). Samples were either assayed directly to quantitate active TGF- $\beta 1$ or following acid activation, a process that activates any latent TGF- $\beta 1$ and therefore allows measurement of total (latent plus active) TGF- $\beta 1$. For the ELISA, plates were coated overnight with a monoclonal antihuman TGF- $\beta 1$ antibody, washed, and then blocked. The standards and samples were added for two hours and then incubated for a further two hours with biotinylated antihuman TGF- $\beta 1$ antibody. Streptavadin HRP (Cambridge Bioscience, Cambridge, UK) and then tetramethyl benzidine solution along with a peroxidase substrate (Sigma, Poole, UK) were used for detection. Colour development was stopped by sulphuric acid and the plate read at $540 \mathrm{~nm}$.

IN VIVO MODEL OF HEPATIC FIBROSIS

To determine the effect of relaxin in vivo, hepatic fibrosis was induced by carbon tetrachloride $\left(\mathrm{CCl}_{4}\right)$ over a 28 day experimental period in the presence of relaxin delivered by an osmotic minipump.

Twenty eight day osmotic minipumps (Model No 2ML4; Alza Corporation, Palo Alto, California, USA) were loaded with $2.0 \mathrm{ml}$ of $0.2 \mathrm{mg} / \mathrm{ml}$ relaxin or PBS (control). Pumps were implanted subcutaneously under isoflurane anaesthesia in male Sprague-Dawley rats weighing 200-300 g. Six animals received PBS and $\mathrm{CCl}_{4}$ for 28 days (control) and six animals received relaxin and $\mathrm{CCl}_{4}$ for 28 days (relaxin treated). The osmotic minipumps delivered a sustained relaxin dose of approximately 0.5 $0.6 \mathrm{mg} / \mathrm{kg} /$ day. Animals were injected intraperitoneally with $0.2 \mathrm{ml} / 100 \mathrm{~g}$ sterile $\mathrm{CCl}_{4}$ in a $1: 1$ ratio with olive oil twice weekly. All animals received humane care with free access to standard chow and water. The study complied with UK Home Office guidelines and rats were monitored daily for general health. At the end of the study period, the animals were killed, blood collected for determination of serum relaxin concentrations (determined by ELISA at Connetics Corp.), and the livers removed and weighed.

The hydroxyproline content of each liver was determined as previously described ${ }^{27}$ with minor modifications.

\section{Results}

RELAXIN REDUCES COLLAGEN SYNTHESIS AND DEPOSITION BY CULTURE ACTIVATED HSC The in vitro effect of relaxin on HSC collagen secretion was quantified by Sirius red dye binding and spectrophotometry. Incubation of
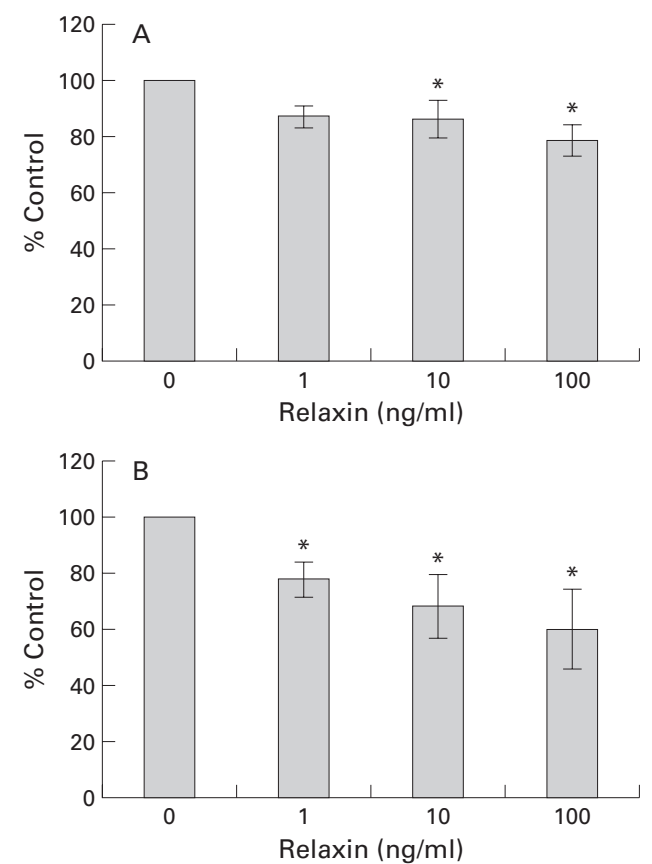

Figure 1 Effect of relaxin on hepatic stellate cell (HSC) collagen deposition. Primary HSC were cultured in the presence of relaxin at three concentrations. (A) Collagen deposition on tissue culture plates quantified by Sirius red binding, as described in the methods. Relaxin treated HSC are shown in comparison with untreated controls (defined as $100 \%$ ). The results are mean percentage change observed in seven independent experiments $\left({ }^{*} p<0.05\right.$, paired t test). (B) Effect of relaxin on collagen synthesis determined by ${ }^{3} \mathrm{H}$ proline incorporation. The results are mean percentage observed in five independent experiments $\left({ }^{*} p<0.05\right.$ by paired $t$ test $)$.

HSC for 48 hours with relaxin induced a modest but consistent dose dependent reduction in the amount of collagen deposited on tissue culture plates (fig 1A) $(0.05>p>0.01, n=7$, for relaxin 10 and $100 \mathrm{ng} / \mathrm{ml}$ compared with control by paired $t$ test). The effect of relaxin on collagen synthesis by activated HSC was examined by radiolabelled proline incorporation into collagens present in the tissue culture supernatant. Treatment with relaxin (100 $\mathrm{ng} / \mathrm{ml}$ ) resulted in a $40 \%$ decrease in collagen synthesis over a 24 hour period (fig 1B) $(0.05>p>0.01, n=5$, for relaxin 1,10 , and 100 $\mathrm{ng} / \mathrm{ml}$ compared with control by paired $t$ test). A confirmatory experiment assessing collagen synthesis by ${ }^{3} \mathrm{H}$ proline incorporation was performed on passaged human HSC in which culture with relaxin $(100 \mathrm{ng} / \mathrm{ml})$ for 24 hours led to a $71 \%$ reduction in collagen production.

SECRETED TIMP-1 AND TIMP-2 ARE REGULATED BY EXPOSURE OF HSC TO RELAXIN

Zymographic techniques were used to examine MMP and TIMP secretion by HSC (fig 2). After 24 hours of relaxin exposure, a concentration dependent reduction in TIMP-1 and TIMP-2 was observed. Gelatinase A and B were constitutively secreted by activated HSC (fig 2). However, relaxin did not induce a change in the secretion of either the zymogen or active forms of gelatinase A or B. No activity attributable to secreted rat interstitial collagenase MMP-13 was observed by zymography in any of the experiments performed. Moreover, no collagenase activity was detected in ${ }^{14} \mathrm{C}$ 

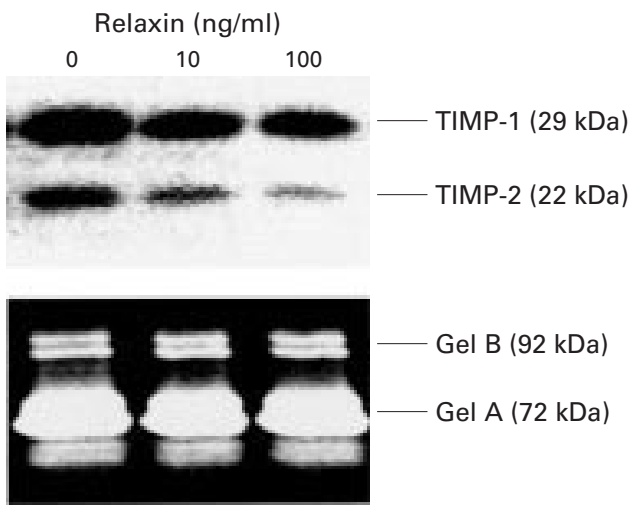

Figure 2 Identification of gelatinase ( $\mathrm{Gel}$ ) $A$ and $B$ by zymography and tissue inhibitor of metalloproteinases 1 and 2 (TIMP-1 and TIMP-2) by reverse zymography in conditioned media from cultured hepatic stellate cells (HSC). Five day cultures of primary HSC were incubated in serum free conditions with varying relaxin concentrations for 24 hours. The supernatants were subjected to zymography and reverse zymography, as described in the methods. After staining with Coomassie blue, bands corresponding to the expected molecular weight of gelatinase $B(92 \mathrm{kDa})$ and gelatinase $A(72 \mathrm{kDa})$ were observed. No evidence of matrix metalloproteinase 13 activity was detected. Addition of activated metalloproteinases to the incubation buffer revealed dark bands on a light background corresponding to the expected molecular weights of TIMP-1 (29 kDa) and TIMP-2 (22 kDa).

Densitometric analysis of this reverse zymogram indicates that TIMP-1 was reduced by $48 \%$ and TIMP-2 by $83 \%$ in response to $100 \mathrm{ng} / \mathrm{ml}$ relaxin. The results are

representative of two independent experiments.

labelled collagen fibril assays in the conditioned media of HSC that had been exposed to relaxin $(100 \mathrm{ng} / \mathrm{ml})$ for between one and three days, or in any of the control cultures.

TIMP-1 BUT NOT TYPE I COLLAGEN mRNA IS REGULATED BY RELAXIN

To investigate whether relaxin regulates type I collagen mRNA levels, HSC were cultured in the presence or absence of varying concentrations of relaxin. Total RNA was subjected to northern blotting and then probed for type I collagen mRNA. This revealed no significant difference in type I collagen mRNA expression with exposure to relaxin for periods of up to seven days in three independent experiments (fig 3). Furthermore, no significant change in mRNA expression for either rat interstitial collagenase (MMP-13) or $\alpha$-SMA was detected in three independent experiments. However, exposure to $100 \mathrm{ng} / \mathrm{ml}$ relaxin led to a modest reduction in TIMP-1 mRNA expression; densitometric analysis indicated a 38\% decrease relative to $\beta$-actin in response to $100 \mathrm{ng} / \mathrm{ml}$ of relaxin (mean of two independent experiments).

RELAXIN DOES NOT MEDIATE EXPRESSION OR ACTIVATION OF TGF- $\beta 1$ IN HSC

As the decrease in collagen deposition and downregulation of TIMP-1 observed in relaxin treated culture activated HSC are consistent with TGF- $\beta 1$ downregulation, expression and activation of TGF- $\beta 1$ were determined. Northern analysis of RNA from activated primary or early passage HSC that had been continuously cultured with relaxin $100 \mathrm{ng} / \mathrm{ml}$ for between one and five days demonstrated no alteration in

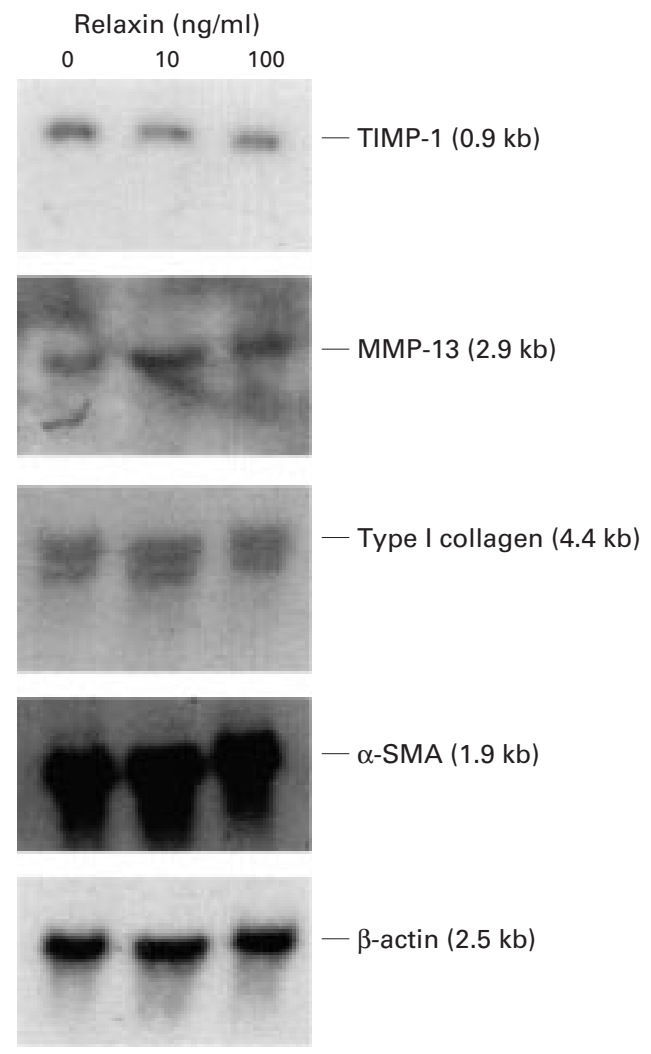

Figure 3 Northern blot analysis of hepatic stellate cells (HSC) cultured with a series of concentrations of relaxin. Total RNA was extracted from primary HSC cultured for seven days in the presence or absence of relaxin. Northern analysis was performed and the membranes probed sequentially with $\left[a^{-32} \mathrm{P}\right]$ labelled random primed $c D N A$ probes, as described in the methods. The results are representative of two independent experiments. TIMP-1, tissue inhibitor of metalloproteinase $1 ; M M P-13$, matrix metalloproteinase 13; a-SMA, alpha smooth muscle actin.

TGF- $\beta 1$ mRNA expression relative to control cultures (fig 4). The amount of secreted TGF- $\beta 1$ present in conditioned media from cultured HSC was quantified by ELISA. Figure 5 shows representative results of one of three independent experiments using primary HSC, demonstrating that there was no change in the levels of active (fig 5A) or latent (total-active) (fig $5 \mathrm{~B}$ ) TGF- $\beta 1$ in response to culture with relaxin for 24-72 hours. Similarly, no change in latent or active TGF- $\beta 1$ secretion into conditioned media was seen in early passage HSC exposed to relaxin compared with control cultures $(n=2)$. A single further experiment was performed on passaged human HSC, and again no differences in the levels of active or total TGF- $\beta 1$ were seen in the conditioned media of human HSC exposed to relaxin $100 \mathrm{ng} / \mathrm{ml}$ for 24 hours.

RELAXIN REDUCES COLLAGEN DEPOSITION IN AN IN VIVO MODEL OF HEPATIC FIBROSIS

The in vivo effect of relaxin on the development of hepatic fibrosis was examined using the rat $\mathrm{CCl}_{4}$ model and continuous subcutaneous infusion of recombinant relaxin. The effective delivery of relaxin was confirmed by measurement of serum relaxin in the treatment group at the end of the experimental period. The mean serum relaxin level was $18.8 \mathrm{ng} / \mathrm{ml}$ 
A
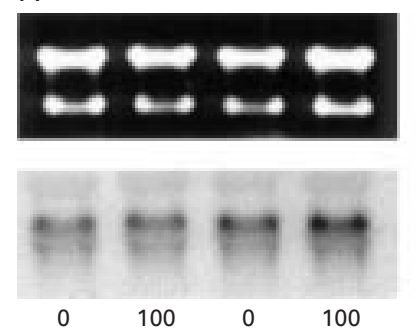

Relaxin (ng/ml)

B
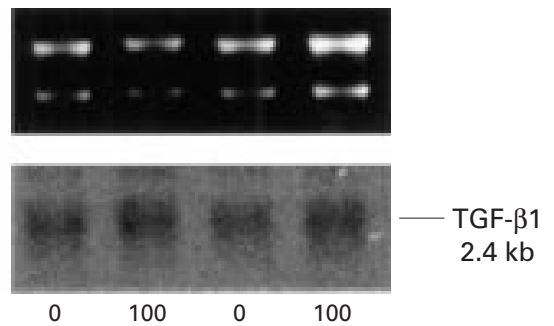

$2.4 \mathrm{~kb}$ hepatic stellate cells (HSC) cultured in the presence or absence of relaxin $(100 \mathrm{ng} / \mathrm{ml}$ for 24 hours). Total RNA was extracted from day 5 primary HSC $(A)$ or passaged P1 HSC $(B)$ and $10 \mu \mathrm{g}$ aliquots were subjected to northern blotting and probed for $T G F-\beta 1$. The bottom panel shows the northern blots and the top panel ethidium bromide staining of the $28 S$ and $18 \mathrm{~S}$ ribosomal bands as a control.
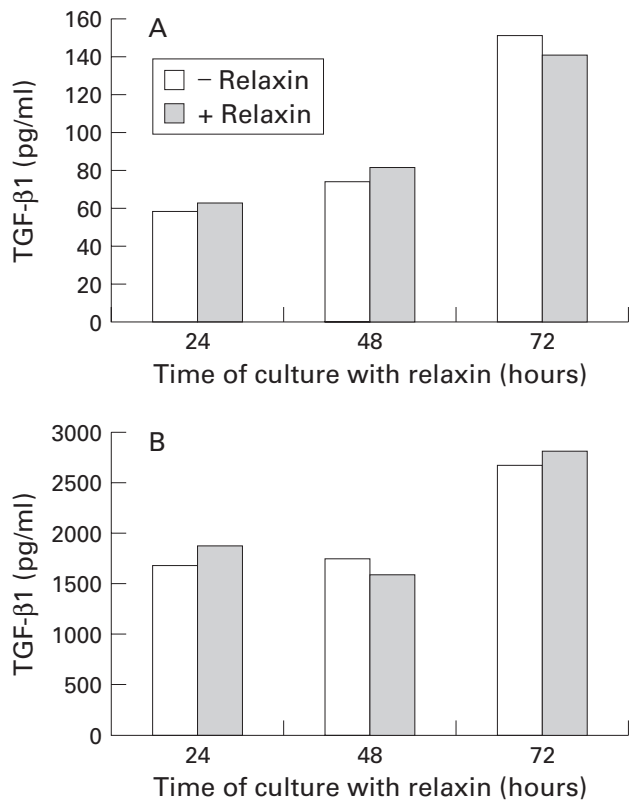

Figure 5 Transforming growth factor $\beta 1$ (TGF- $\beta 1)$ levels in the conditioned media of cultured HSC. Primary (day 5) hepatic stellate cells cultured in serum free conditions were incubated in the presence $(+)$ or absence $(-)$ of relaxin $100 \mathrm{ng} / \mathrm{ml}$ for $24-72$ hours and the total amount of active and latent TGF- $\beta 1$ determined as described. Levels of active TGF- $\beta 1$ are represented in $(A)$ and latent (total-active) TGF- $\beta 1$ in (B). Results shown are representative of one of three independent experiments.

(range 0.7-41.7). Relaxin is undetectable in the serum of untreated male rats. After 28 days of $\mathrm{CCl}_{4}$ intoxication, relaxin treatment resulted in a significant decrease in liver weight relative to control livers (expressed as mean (SEM), relaxin treated $17.8(0.57) \mathrm{g} v$ controls 20.1 (0.56) $\mathrm{g} ; \mathrm{p}>0.05$ by Mann-Whitney; $\mathrm{n}=6$ for each group). Hepatic hydroxyproline levels were reduced in the relaxin treated group relative to controls (relaxin treated 1.29 (0.06) $\mu \mathrm{mol} / \mathrm{g}$ wet weight $v$ control $1.85(0.12) \mu \mathrm{mol} / \mathrm{g}$ wet weight). In a further assay, the hydroxyproline content of normal rat liver was determined as 0.95 relaxin $\mu \mathrm{mol} / \mathrm{g}$ wet weight $(\mathrm{n}=3)$. The total liver hydroxyproline content of the relaxin treated livers was significantly decreased relative to controls (relaxin treated 22.9 (1.7) v control 37.2 (2.9) $\mu \mathrm{M} ; \mathrm{p}<0.01$ by MannWhitney test; $\mathrm{n}=6$ for each group)

\section{Discussion}

We have presented data demonstrating that recombinant human relaxin reduces the effective deposition of interstitial collagen in both tissue culture and in an in vivo model of hepatic fibrosis. In vitro, we examined the effects of relaxin on HSC, as the HSC has been clearly identified as having a major role in matrix homeostasis in hepatic fibrogenesis. HSC cultured on plastic assume an activated phenotype, characterised by elevated type I collagen, TIMP-1, and TGF- $\beta 1$ expression. Our results demonstrate that culture activated HSC treated with relaxin show a consistent dose dependent decrease in the deposition of collagen compared with control cultures. We endeavoured to determine the mechanisms underlying these changes and so examined the protein biosynthetic levels of type I collagen, MMP-13, TIMP-1, TIMP-2, and TGF- $\beta 1$. We have also described the effect of relaxin on levels of transcripts of type I collagen, MMP-13, TIMP-1, and $\alpha$-SMA. Overall, our results suggest that in this model relaxin mediates a reduction in collagen deposition directly by reducing type I collagen protein synthesis, and indirectly by decreasing TIMP-1 and TIMP-2 expression, thereby potentially enhancing matrix degradation. Moreover, our data indicate that this effect is not mediated via downregulation of TGF- $\beta 1$ expression. Finally, relaxin was tested in a well established and reproducible animal model of hepatic fibrosis to examine its effect on the development of liver fibrosis in vivo. Consistent with our cell culture data, our results in this pilot study demonstrated that treatment with relaxin led to a decrease in liver size in response to fibrotic injury associated with a significant decrease in total liver hydroxyproline content.

In vitro, culture of primary HSC on plastic is an established model which mimics the phenotypic changes that occur during the process of HSC activation following liver injury. Collagen deposition in cell monolayers was assessed using the Sirius red dye binding assay which demonstrated a statistically significant decrease in the amount of collagen laid down by primary HSC cultured in the presence of relaxin. To determine whether the deposition was related to a decrease in collagen synthesis, we examined collagen synthesis using radiolabelled proline incorporation over a limited period of time in HSC cultured with and without relaxin. Both assays gave a clear reproducible and statistically significant effect on collagen synthesis and secretion, demonstrating that relaxin decreases both the rate of collagen synthesis and total collagen deposition by culture activated HSC.

Northern analysis was used to assess type I collagen gene expression in culture activated primary HSC, to determine whether relaxin regulated type I collagen at the level of mRNA. No consistent change was found as a consequence of culture with relaxin, a result that differs from observations in human skin fibroblasts. ${ }^{15}$ Although type I collagen mRNA levels may be regulated by protein mediated 
changes in stability, ${ }^{28}$ continuous relaxin exposure for up to seven days from the time of HSC isolation failed to elicit any changes in mRNA. These results suggest that relaxin regulates collagen deposition at the translational or post-translational level in these cells. Moreover, effective deposition may also depend on changes in the rate of matrix degradation

We went on to examine expression of metalloproteinases and TIMPs by HSC as they may directly regulate collagen levels via matrix degradation and turnover. In keeping with the hypothesis that relaxin induces a matrix degrading phenotype in HSC, a modest but consistent decrease in TIMP- 1 mRNA expression and a clear dose dependent reduction in secreted TIMP-1 and TIMP-2 activity, as determined by reverse zymography, was demonstrated following relaxin exposure. This result is significant in light of the potential importance of the metalloproteinase inhibitors, particularly TIMP-1, in the progression of liver fibrosis in vivo ${ }^{8212930}$ and in the acquisition of the activated HSC phenotype in vitro. ${ }^{82}$ A direct effect of relaxin on fibroblast expression of TIMP is already documented. ${ }^{15} 3132$ However, we detected no relaxin mediated enhancement of collagenase (MMP13) expression. These findings do not exclude critical matrix degradation occurring in a focused and local manner immediately adjacent to HSC. Urokinase plasminogen activator activity and thus plasminogen activation has been localised to the cell surface in HSC. ${ }^{33}$ Gelatinase A and B, which are constitutively secreted by HSC in the presence of relaxin, have been demonstrated to have weak collagenolytic activity ${ }^{34}$ but were not regulated by relaxin.

We explored the hypothesis that the observed antifibrotic effects of relaxin may be mediated via downregulation of endogenous TGF- $\beta 1$. The relaxin and TGF- $\beta 1$ systems can be viewed as being mutually antagonistic in their effects. Moreover, TGF- $\beta 1$ is expressed by HSC in an autocrine manner and upregulates TIMP-1 expression. ${ }^{35}{ }^{36}$ Relative to control, TGF- $\beta 1$ mRNA expression was unchanged in primary and early passage HSC exposed to relaxin and also there were no differences in secretion of latent TGF- $\beta 1$ in response to relaxin. This suggests that the effect of relaxin in HSC is not mediated via TGF- $\beta 1$.

Finally, relaxin was tested for its effects in $\mathrm{CCl}_{4}$ induced liver fibrosis in rats. Relaxin treatment induced a significant reduction in both liver weight and overall hydroxyproline content relative to controls. These data indicate that the observed effects of relaxin on collagen and TIMP expression in tissue culture are reflected in an in vivo model of hepatic fibrosis. Serum levels of relaxin achieved were greatly in excess of physiological levels in the human which peak at 900 $\mathrm{pg} / \mathrm{ml}$ in the first trimester of pregnancy. ${ }^{37}$ The decrease in liver hydroxyproline content in this model is comparable with that seen in rodent models of pulmonary fibrosis treated with relaxin ${ }^{18}$ but less dramatic than that observed with rodent dermal fibrosis. ${ }^{17}$ Taken together, the data suggest that recombinant human relaxin modulates connective tissue deposition in rodent models of fibrosis although by crossing species the effect may be attenuated. Nevertheless, these studies represent proof of concept for the need to further evaluate the effectiveness of relaxin in fibrotic models. More detailed studies of the role of relaxin in modulating a pre-existing fibrotic injury are proposed.

In summary, our results are consistent with the previously reported ability of relaxin to inhibit collagen deposition and promote collagen degradation in circumstances where collagen is overexpressed. The magnitude of change that we report is similar to that observed in other rodent studies. ${ }^{17}{ }^{18}$ Our studies represent a proof of concept that relaxin is worthy of further study as an agent capable of modifying fibrosis in the liver.

This work was supported by the Medical Research Council (grant No G84/4764 supporting Dr EJ Williams). JP Iredale is an MRC Senior Clinical Fellow and a member of an MRC
cooperative group and gratefully acknowledges the support of the British Liver Trust and the Wessex Medical Trust.

1 Friedman SL. The cellular basis of hepatic fibrosis: Mechanisms and treatment strategies. $N$ Engl ${ }_{f} \mathrm{Med}$ 1993;328:1828-35.

2 Alcolado R, Arthur MJP, Iredale JP. Pathogenesis of liver fibrosis. Clin Sci 1997;92:103-12.

3 Maher JJ,McGuire RF. Extracellular matrix gene expression increases preferentially in rat lipocytes and sinusoidal endothelial cells during hepatic fibrosis in vivo. 7 Clin Invest 1990;86:1641-8.

4 Friedman SL, Roll FJ, Boyles J, et al. Hepatic lipocytes: The principal collagen-producing cells of normal rat liver. Proc principal collagen-producing cells of
Natl Acad Sci USA 1985;82:8681-5.

5 Arthur MJP, Friedman SL, Roll FJ, et al. Lipocytes from normal rat liver release a neutral metalloproteinase that degrades basement membrane (type IV) collagen. I Clin Invest 1989;84:1076-85.

6 Benyon RC, Iredale JP, Ferris WF, et al. Increased expression of mRNA for gelatinase A and TIMP-2 in human fibrotic liver disease. Hepatology 1993;18:198A.

7 Vyas SK, Leyland H, Gentry J, et al. Transin (stromelysin) is expressed in early rat lipocyte primary culture. Gastroenterology 1995;109:889-98.

8 Iredale JP, Murphy G, Hembry RM, et al. Human hepatic lipocytes synthesize tissue inhibitor of metalloproteinases-1 (TIMP-1): Implications for regulation of matrix degrada(TIMP-1): Implications for regulation of
tion in liver. $\mathcal{F}$ Clin Invest 1992;90:282-7.

9 Benyon RC, Iredale JP, Goddard S, et al. Expression of Benyon RC, Iredale JP, Goddard S, et al. Expression of
tissue inhibitor of metalloproteinases- 1 and -2 is increased in fibrotic human liver. Gastroenterology 1996;110: $821-31$

10 Wiqvist I, Norstrom A, O’Byrne E, et al. Regulatory influence of relaxin on human cervical and uterine connective tissue. Acta Endocrinol (Copenh) 1984;106:127-32.

11 Bryant-Greenwood GD, Schwabe C. Human relaxins: chemistry and biology. Endocr Rev 1994;15:5-26.

12 Bani D. Relaxin: a pleiotropic hormone. Gen Pharmacol 1997;28:13-22.

13 Chihal HJ, Espey LL. Utilization of the relaxed symphysis pubis of guinea pigs for clues to the mechanism of ovulation. Endocrinology 1973;93:1441-5.

14 Too CK, Kong JK, Greenwood FC, et al. The effect of oestrogen and relaxin on uterine and cervical enzymes: trogen and relaxin on uterine and cervical enzymes: Endocrinol (Copenh) 1986;111:394-403.

15 Unemori EN, Amento EP. Relaxin modulates synthesis and secretion of procollagenase and collagen by human dermal fibroblasts. $\mathcal{F}$ Biol Chem 1990;265:10681-5.

16 Unemori EN, Bauer EA, Amento EP. Relaxin alone and in conjunction with interferon-gamma decreases collagen synthesis by cultured human scleroderma fibroblasts. $f$ Invest Dermatol 1992;99:337-42.

17 Unemori EN, Beck LS, Lee WP, et al. Human relaxin decreases collagen accumulation in vivo in 2 rodent models of fibrosis. F Invest Dermatol 1993;101:280-5.

18 Unemori EN, Pickford LB, Salles AL, et al. Relaxin induces an extracellular matrix-degrading phenotype in human lung fibroblasts in vitro and inhibits lung fibrosis in a murine model in vivo. $\mathcal{f}$ Clin Invest 1996;98:2739-45.

19 Garber SL, Mirochnik Y, Singh AK, et al. Relaxin decreases interstitial fibrosis: a novel treatment to slow progression of renal disease f Am Soc Nephrol 1999;10:659A. 
20 Taylor MJ, Clark CL. Transforming growth factor-beta is a potent inhibitor of basal and stimulated relaxin release by porcine luteal cells maintain

21 Iredale JP, Goddard S, Murphy G, et al. Tissue inhibitor of metalloproteinase- 1 and interstitial collagenase expression in autoimmune chronic active hepatitis and activated human hepatic lipocytes. Clin Sci 1995;89:75-8

22 Sweat F, Puchtler H, Rosenthal SI. Sirius red F3BA as a stain for connective tissue. Arch Pathol 1964;78:69-72.

23 Postlethwaite AE, Smith GN, Mainardi CL, et al. Lymphocyte modulation of fibroblast function in vitro: stimulation and inhibition of collagen production by different effector molecules. F Immunol 1984;132:2470-7.

24 Cairns JA, Walls AF. Mast cell tryptase stimulates the synthesis of type I collagen in human lung fibroblasts. $\mathcal{F}$ Clin Invest 1997;99:1313-21.

25 LaBarca C, Paigen K. A simple, rapid, and sensitive DNA assay procedure. Anal Biochem 1980;102:344-52.

26 Chomczynski P, Sacchi N. Single-step method of RNA isolation by acid guanidinium thiocyanate-phenol-chloroform extraction. Anal Biochem 1987;162:156-9.

27 Bergman I, Loxley R. Two improved and simplified methods for the spectrophotometric determination of hydroxyproline. Anal Chem 1963;35:1961-5.

28 Stefanovic B, Hellerbrand C, Holcik M, et al. Posttranscriptional regulation of collagen alpha 1(I) mRNA in hepatic stellate cells. Mol Cell Biol 1997;17:5201-9.

29 Arthur MJP, Iredale JP, Murphy G. Tissue inhibitor of metalloproteinase-1 is expressed by culture activated human hepatic lipocytes and in fibrotic human liver. $Q \mathcal{F}$
Med 1993;86:546-7.
30 Iredale JP, Benyon RC, Arthur MJP, et al. Tissue inhibitor of metalloproteinase-1 messenger RNA expression is enhanced relative to interstitial collagenase messenger RNA in experimental liver injury and fibrosis. Hepatology 1996;24:176-84.

31 Qin X, Chua PK, Ohira RH, et al. An autocrine/paracrine role of human decidual relaxin. II. Stromelysin- 1 (MMP-3) and tissue inhibitor of matrix metalloproteinase-1 (TIMP-1). Biol Reprod 1997;56:812-20.

32 Lenhart JA, Ohleth KM, Ryan PL, et al. Effect of relaxin on tissue inhibitor of metalloproteinase- 1 and -2 in the porcine uterus and cervix. Ann N Y Acad Sci 1999;878:565-6.

33 Leyland H, Gentry J, Arthur MJP, et al. The plasminogenactivating system in hepatic stellate cells. Hepatology 1996; 24:1172-8.

34 Aimes RT, Quigley JP. Matrix metalloproteinase-2 is an interstitial collagenase-Inhibitor-free enzyme catalyzes the cleavage of collagen fibrils and soluble native type I collagen generating the specific $3 / 4-$ and $1 / 4$-length fragments. F Biol Chem 1995;270:5872-6.

35 Edwards DR, Murphy G, Reynolds JJ, et al. Transforming growth factor beta modulates the expression of collagenase and metalloproteinase inhibitor $E M B O \quad 7$ 1987;6: 1899-904.

36 Overall CM, Wrana JL, Sodek J. Transcriptional and post-transcriptional regulation of $72-\mathrm{kDa}$ gelatinase/type IV collagenase by transforming growth factor-betal in human fibroblasts. F Biol Chem 1991;266:14064-71.

37 Bani D. Relaxin: a pleiotropic hormone. Gen Pharmacol 1997;28:13-21. 